\title{
Universal Database Integration System
}

\author{
Jaya Chandna ${ }^{1}$, Dr. Ritu Sindhu ${ }^{2}$ \\ ${ }^{1} \mathrm{M}$. Tech $4^{\text {th }}$ Sem Student (Computer Science and Engineering) SGT University, Gurgaon \\ ${ }^{2}$ Associate Professor, SGT University, Gurgaon
}

\begin{abstract}
This application can be extended so that it will give maximum performance including the security related aspects, it can be let go as a product in the open market. As it has got very user friendly look and feel, it will be definitely succeeded in the market as a Product Database Interface is an industry-standard tool for application development. Using this Database Interface, developers can easily interact with any back end software (i.e. Oracle, MS-SQL Server, My-SQL, MS-Access etc.).The database interface can be used to build, test, and debug PL/SQL packages, triggers, procedures, and functions. The users of database interface can create and edit the database objects such as tables, indexes, views, constraints, and users. Database Interface provides an easy and efficient way to write test scripts, queries and its powerful data grids give an easy way to view and edit data related to any DBMS/RDBMS tool.
\end{abstract}

Keywords: Database, My SQL, Oracle

\section{Introduction}

Database Interface is an industry-standard tool used for application development. By using it, developers can easily interact with any back end software (i.e. MS-Access, Oracle, MS-SQL Server, My-SQL etc). To construct, test, and debug $\mathrm{PL} / \mathrm{SQL}$ packages, triggers, procedures, and functions database interface are used. The users of database interface can create and edit the database objects such as tables, indexes, views, constraints, and users. Database Interface's SQL Editor provides simple and efficient way to test and write scripts and queries, and its powerful data grids gives an easy way to view and edit data that is related to any of DBMS/RDBMS tool.

The requirements of a developer that are using database application will vary from project to project. On a large team where data base administrators handle the data definition language, a developer may spend $90 \%$ of the development time on coding and testing various queries to issue from 3GL or 4GL application code. In this environment, a developer might be concerned only with screening the DDL and database code. On smaller teams, database application developers might be responsible for maintenance of the development schema, movement of data between schemas, populating tables from legacy sources, writing procedure code and more. Database Interface provides all of these needs.

Use for Database Interface

- To create, alter or browse objects (tables, indexes, views etc.) including Oracle8 TYPE Objects

- Graphically execute, build and tune queries

- Edit and Debug PL/SQL and profile "stored procedures" with functions, triggers and packages

- Search for objects

\section{Existing System}

In the development phase, a project manager is dealing with an enterprise application. This application has got various faces just like desktop interface, mobile interface and a web interface. Initially all these applications are not integrated.
Once all these interfaces are working well, they can easily be integrated. In such occurrence the database which is being utilized must be same. But while designing these individual modules, creating a taster database for each module and perform the testing, it is not possible practically. So for that reason, there must be a tool, using this we can carry the database to any another location and can easily use the database there very easily. The present application will accomplish all the requirement. The existing application can be used as a brief case of database.

\section{Proposed System}

The current application can be categorized into the following modules, which are closely linked with one another.

1. Structure This module provides the list of all tables which are present in the selected or current user. This module is used to view and browse the structure of an existing database.

2. Properties In this module we can easily modify data types, constraints and size assigned to each field.

3. SQL By using this module, we can use and create different kinds of SQL

4. statements. The result of the given SQL statement will be displayed immediately after executing it.

5. Import This module is an important feature of importing the existing SQL scripts to the existing ones.

6. Export This module is used for exporting existing the schema to an SQL file. Here we are providing facility to export only tables or the entire schema.

7. Operations This module is be used to create new database objects.

8. Search This module providing facilities for searching for the given column names, data or both options.

\section{Snap Shots}

\section{1) Data Base Log In}

The main entrance to the system is from "Login" page. An ordinary user will login with username and password. If user wants to do work on oracle then user will choose oracle with its driver name and URL else user will choose MY SQL with its URL and its driver name. 


\section{International Journal of Science and Research (IJSR)}

ISSN (Online): 2319-7064

Index Copernicus Value (2013): 6.14 | Impact Factor (2015): 6.391

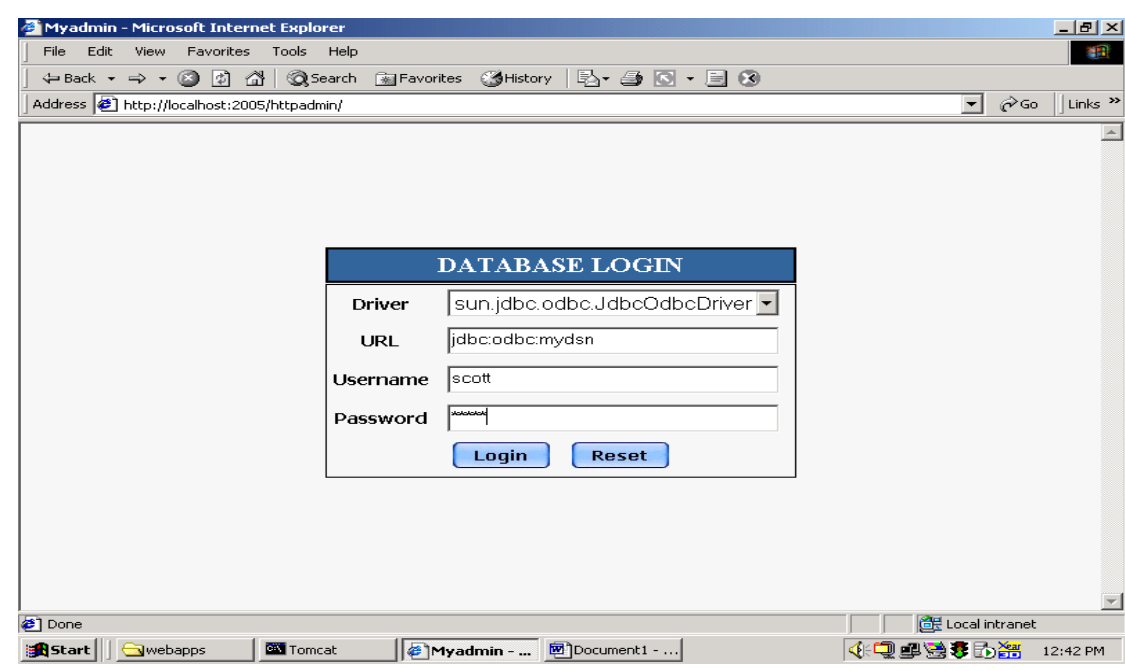

\section{2) Structure of the Database}

It displays the number of records of each table as created by the user. In this structure module, we can perform various actions such as create a new table, enter a data into table, browse the table and modification into table.

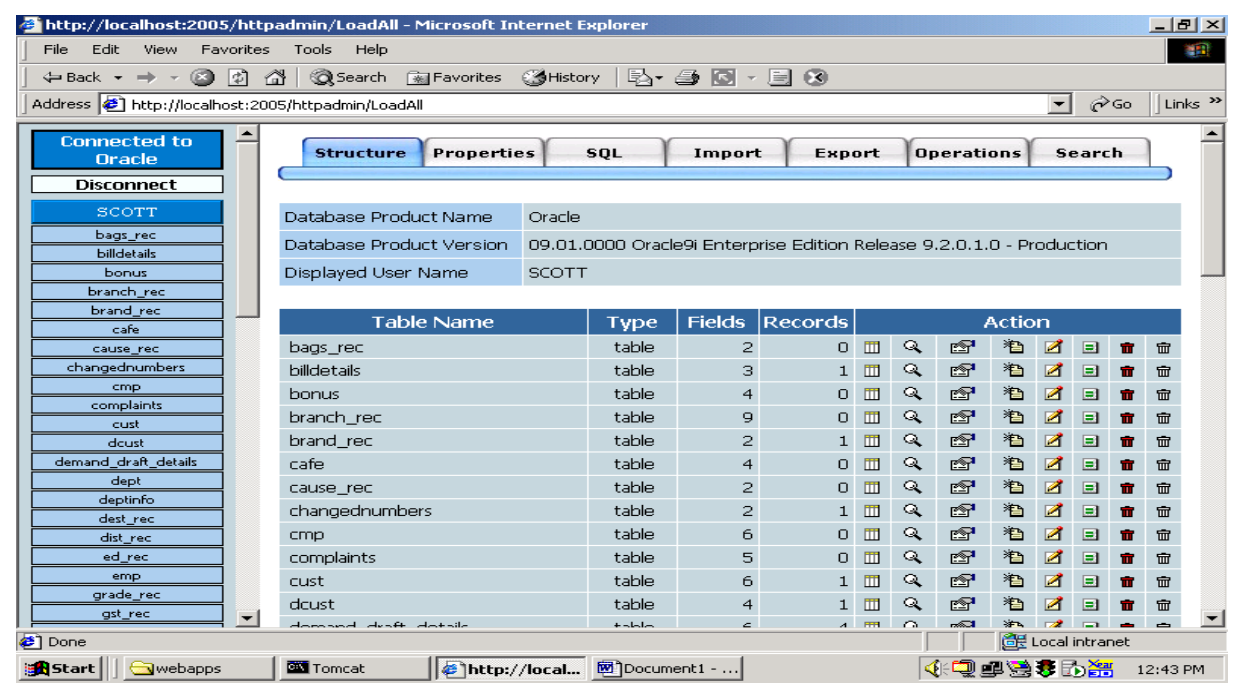

\section{3) SQL Query Panel}

The SELECT clause specifies a list of properties (columns) by name, or the wildcard character (“*”) to mean "all properties".

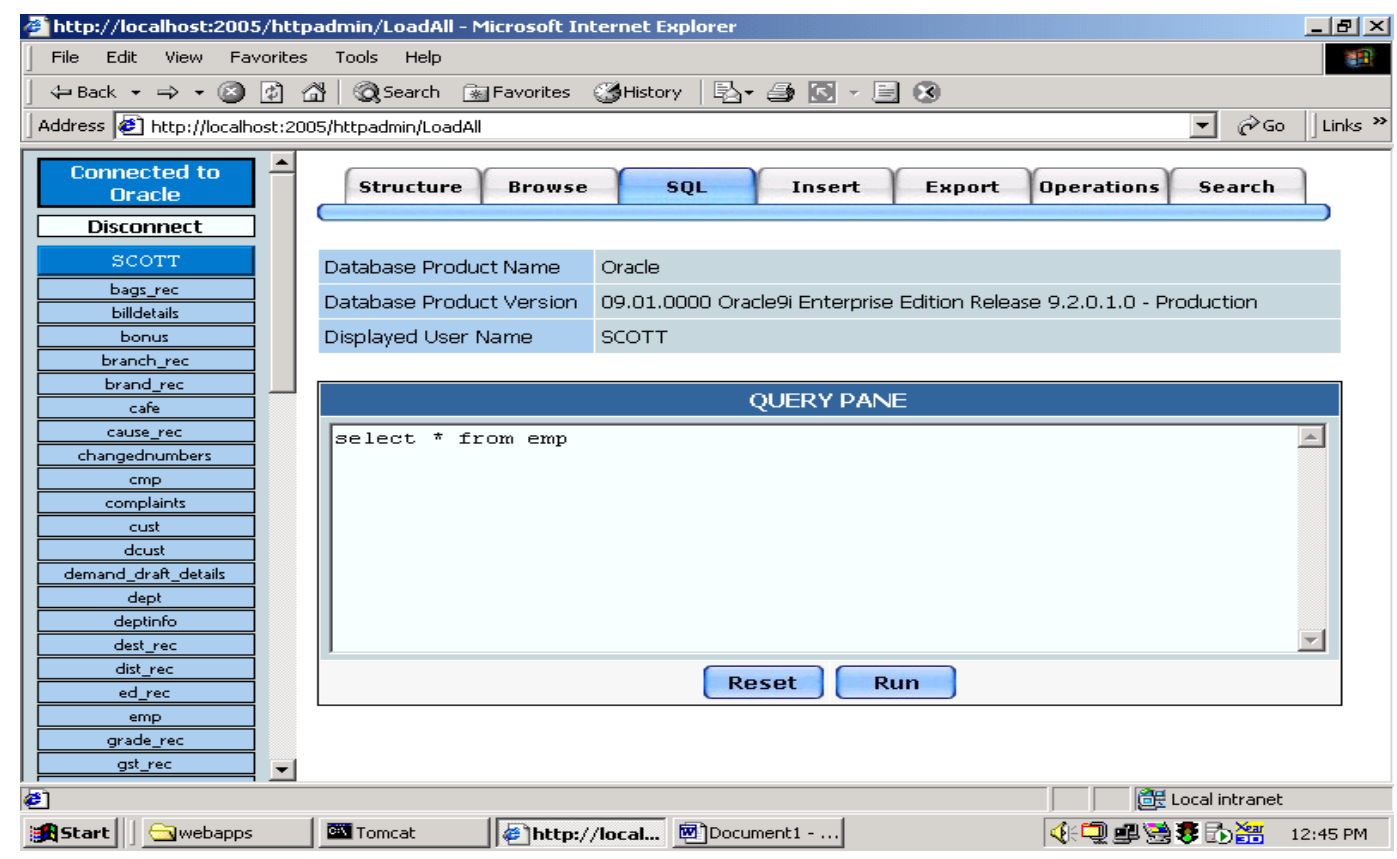

\section{Volume 5 Issue 6, June 2016 www.ijsr.net}

Licensed Under Creative Commons Attribution CC BY 


\section{International Journal of Science and Research (IJSR) \\ ISSN (Online): 2319-7064 \\ Index Copernicus Value (2013): 6.14 | Impact Factor (2015): 6.391}

4) Insert Data into The Table

In our database, we will use insert modules for inserting records to a table.

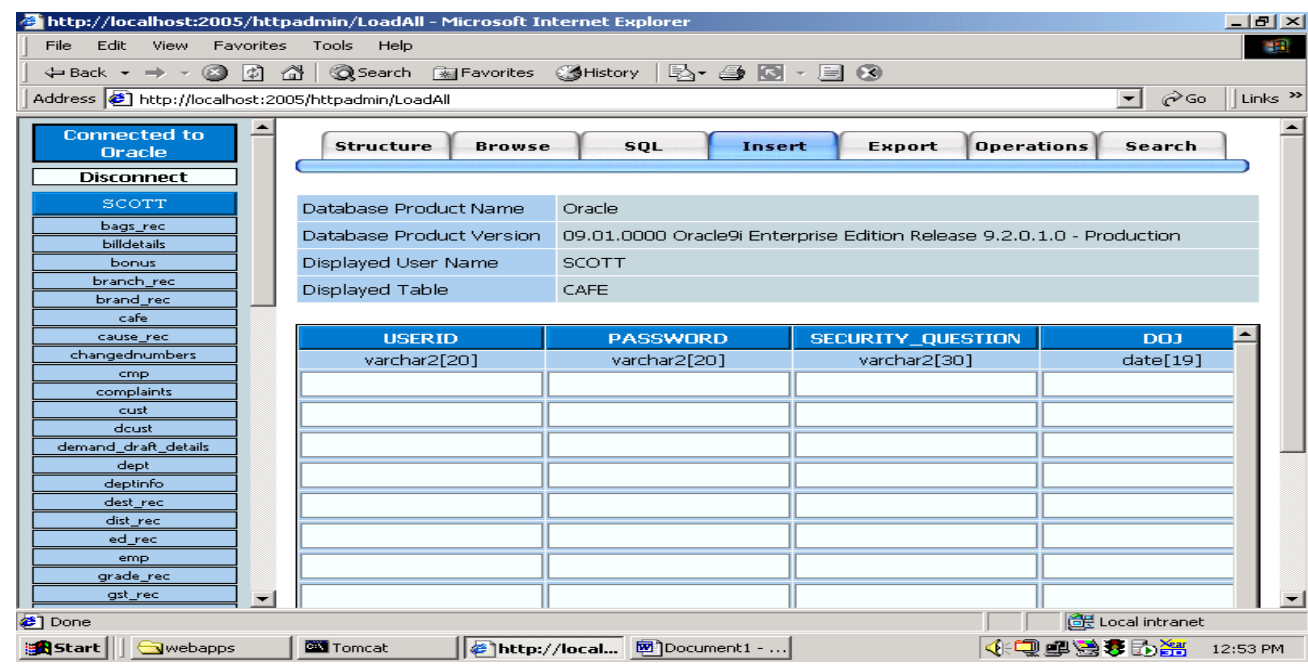

5) Export the Data

This database gives the feature for export existing schema to an SQL file.

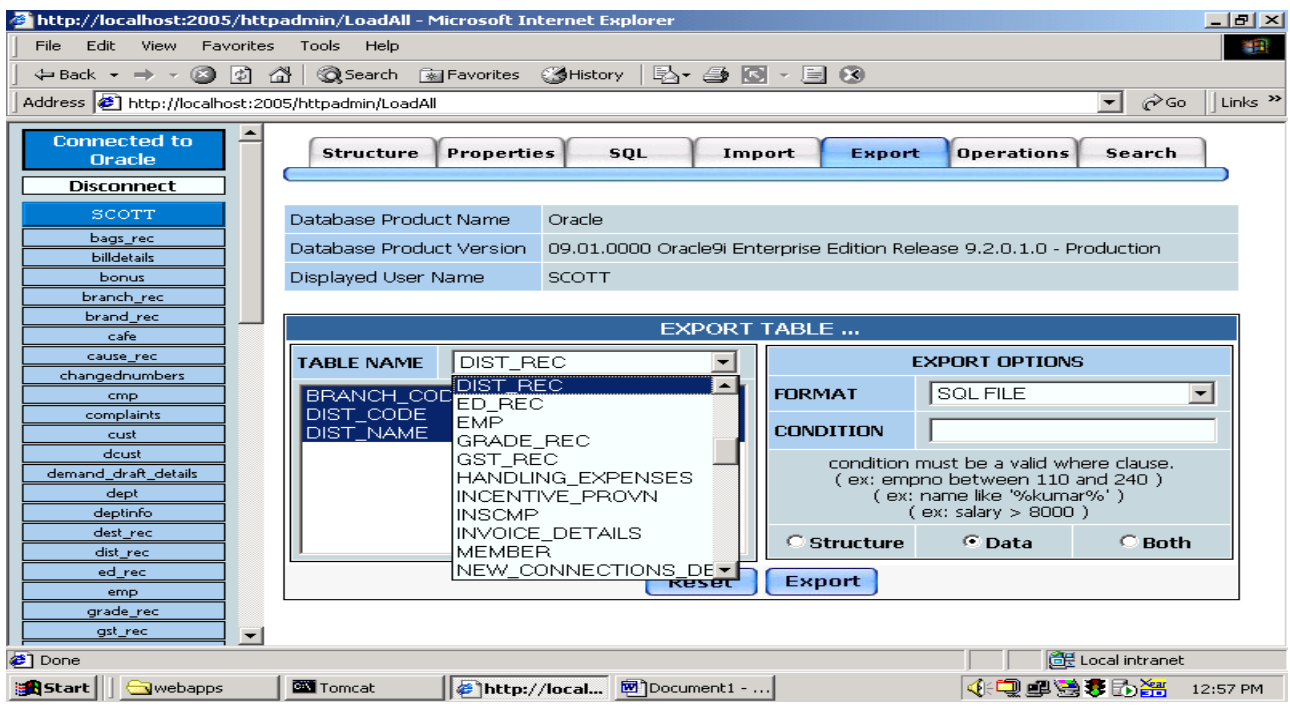

\section{6) Create the Table}

In our database, there is no need to use create statement. We can easily create our table with the help of create module

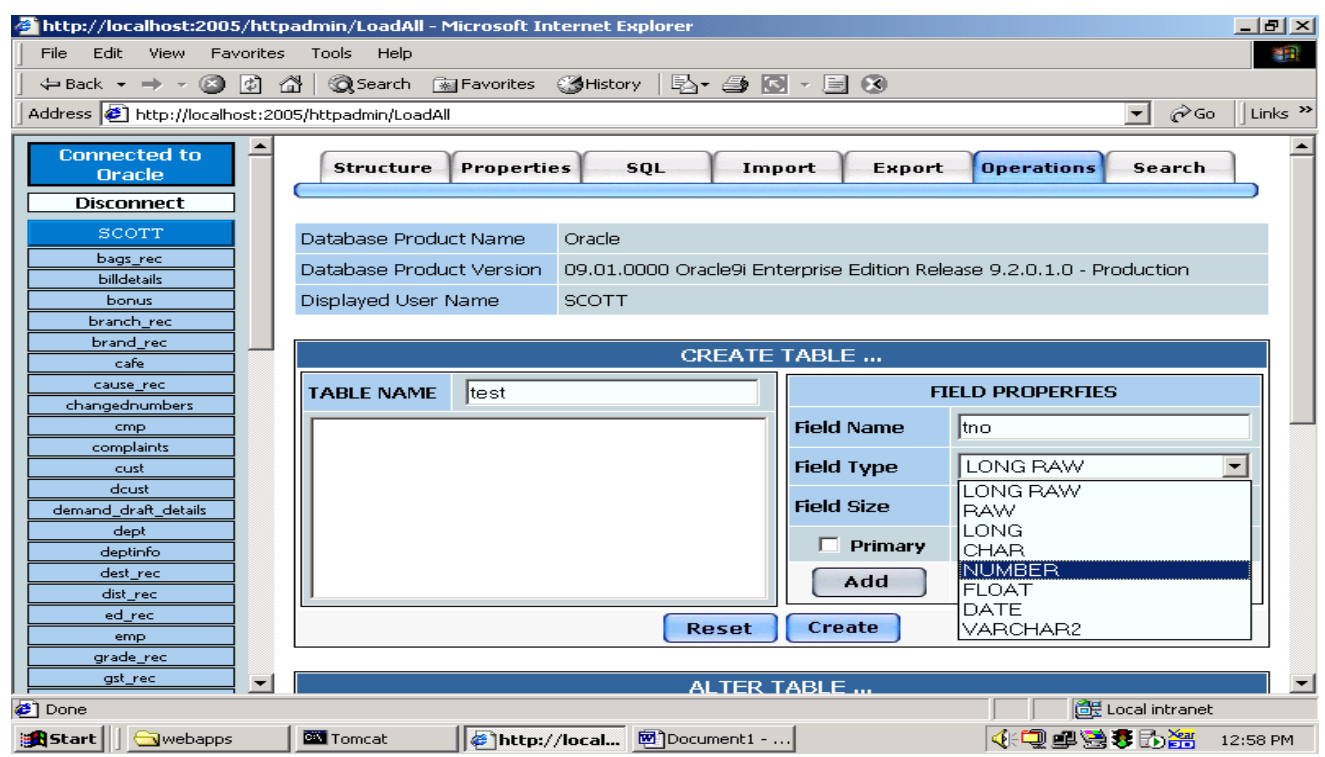

\section{Volume 5 Issue 6, June 2016 www.ijsr.net}

Licensed Under Creative Commons Attribution CC BY 


\section{International Journal of Science and Research (IJSR) \\ ISSN (Online): 2319-7064}

Index Copernicus Value (2013): 6.14 | Impact Factor (2015): 6.391

\section{7) Alter Table}

ALTER TABLE statement is used to add, modify, or drop/delete columns in a table. These options can easily be performed in this database.

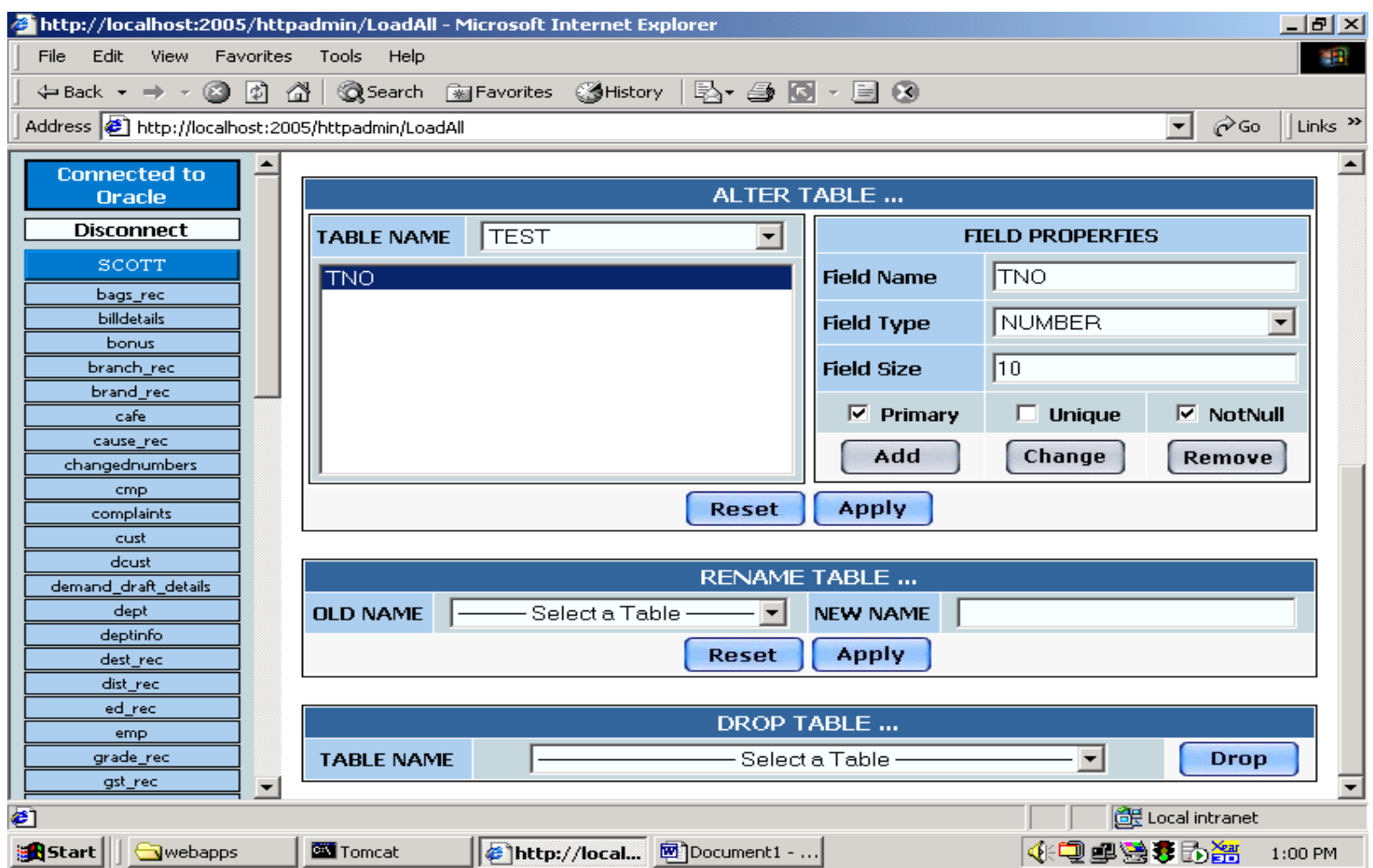

\section{Implementation}

Implementation is the process that having systems personnel check out and put new equipment into use, guide users, install the new app. Depending on the size of the organization that will be involved in using the application and the risk linked with its use, application developers may choose it for testing the operation in only one region of the firm, say in one section or with only one or two persons. Sometimes they will run the new and old application together to compare the results. In other situation, developers will stop using the old system one-day and will start to use the next one. Estimation of the system is carried out to identify its strengths and weakness. The definite evaluation can occur along with any of the following dimensions.

- Operational Evaluation It is the assessment of the manner in which the system functions including response time ease of use, suitability of information formats, overall consistency, and level of utilization.

- Organization Impact Measurement and identification of benefits to the association in such areas as financial concerns with operational efficiency, and viable impact. It adds impact on internal and external information flows.

- User Manager Assessment The evaluation of the attitudes of user mangers and senior within the organization, as well as end-users.

- Development Performance It is the evaluation of the development process in accordance with overall development time and effort, conformance to budgets and standards, and other project management criteria. It includes the estimation of development methods and tools.

\section{Conclusions and Scope for Future}

This application can be extended so that it will give highest performance including the security related aspects, it can be released as a product in the open market.

As it has very user friendly look and feel, it will be definitely succeeded in the market as a product. It will make database user to create, browse, alter, and insert data without typing any SQL query. With the use of this database interface, we can without difficulty import or export the existing SQL scripts to the existing schema.

This product has great future scope. The product made here is just to ensure that this product could be valid in today real challenging world.

\section{References}

[1] The Java2 Complete Referece - By Patric Naughton

[2] Java2 Tutorial - From Sun Micro Systems

[3] Core Java2 Volume I - Fundamentals; SunSoft Press; S. Horstmann \& Gary Cornell

[4] Core Java2 Volume II - Advanced Features SunSoft Press; S. Horstmann \& Gary Cornell

[5] Professional Java Server Programming; Wrox publication; 12 Authors

[6] Java Foundation Classes; Orielly publications

[7] SYSTEM ANALYSIS AND DESIGN James A. Senn

[8] SOFTWARE ENGINEERING Roger S. Pressman

[9] Www.javatpoint.com

[10] www.study2night.com

[11] www.w3school.com 